\title{
Rede de atores e suas influências na informatização da Atenção Básica à Saúde no Brasil
}

\author{
Actor-networks and their influences on the informatization of Primary \\ Healthcare in Brazil (abstract: p. 17)
}

Red de actores y sus influencias en la informatización de la Atención Básica de la Sen Brasil (resumen: p. 17)

\section{Ricardo Bezerra Cavalcante(a)}

<ricardocavalcante@ufsj.edu.br>

Cristiano José da Silva Esteves ${ }^{(\mathrm{b})}$

$<$ cristianoxkm@hotmail.com>

\section{Tarcísio Laerte Gontijo(c)}

<enftarcisio@ufsj.edu.br>

\section{Maria José Menezes Brito ${ }^{(\mathrm{d})}$}

$<$ mj.brito@globo.com>

Eliete Albano de Azevedo Guimarães ${ }^{(e)}$ <elietealbano@hotmail.com>

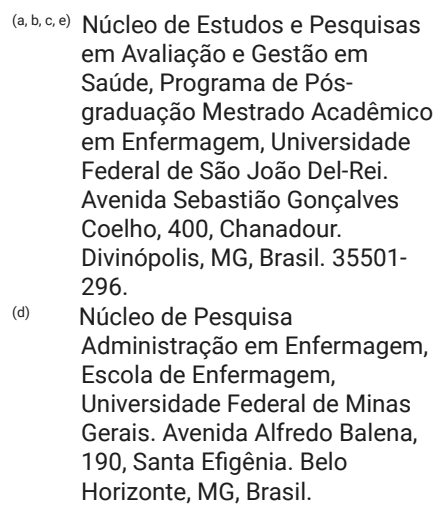

Estudo baseado na Teoria Ator-Rede, que buscou analisar a rede de atores e suas influências sobre a informatização da Atenção Básica à Saúde. A Cartografia de controvérsias direcionou o percurso metodológico, onde atores humanos da esfera municipal, regional, estadual e federal foram observados e entrevistados, além da coleta de documentos publicizados. Os dados foram analisados por meio do software Gephi e por meio da técnica de extratos de relatos com ponto de vista da Teoria Ator-Rede. A rede mapeada é tecida entre humanos e não humanos nas diferentes esferas de governo. Políticas e obrigatoriedades conformaram-se como inscrições norteadoras da informatização, pressionando profissionais e gestores a adequarem processos e tecerem acordos viabilizando a informatização, mas com pouco sucesso. Conclui-se que traduções circunstanciais nas diferentes esferas governamentais influenciaram a informatização da atenção primária, buscando seu sucesso, mas ainda não se mostraram efetivas para tal.

Palavras-chave: Informática em saúde. Tecnologias da informação. Atenção básica à saúde. 


\section{Introdução}

A informatização da Atenção Básica à Saúde (ABS) consiste em implantar tecnologias da informação e comunicação (TIC), automatizando processos gerenciais e assistenciais, e qualificando a gestão da informação ${ }^{1}$. Tal processo tem representado uma importante estratégia em vários países ${ }^{2}$ mas, ao mesmo tempo, se conforma como um grande desafio, sobretudo em países em desenvolvimento como o Brasil, tendo em vista as fragilidades relacionadas a: infraestrutura tecnológica, financiamento, qualificação profissional e organização de processos no contexto do Sistema Único de Saúde (SUS) ${ }^{3,4}$.

O Ministério da Saúde brasileiro, reconhecendo a necessidade de informatização da ABS, instituiu em 2013 a estratégia e-SUS Atenção Básica (e-SUS AB) com a intenção de reestruturar, em nível nacional, todas as informações da Atenção Básica (AB). Essa estratégia visa um SUS eletrônico, o qual possui como premissa, contribuir para a gestão da informação produzida a partir do processo de trabalho das equipes de $\mathrm{ABS}^{5}$.

A estratégia e-SUS AB implica implantar dois sistemas de software: o Coleta de Dados Simplificada (CDS) e o Prontuário Eletrônico do Cidadão (PEC) ${ }^{6}$. Além desses sistemas de software, a implantação da estratégia e-SUS AB visa a disponibilidade de acesso à internet banda larga de alta performance, computadores e impressoras em todos os postos de trabalho, interconectados com outros pontos da rede assistencial em saúde ${ }^{7}$.

De fato, a estratégia e-SUS AB representa possibilidades de avanços e qualificação no uso da informação, mas também desafios a serem suplantados ${ }^{8}$. Devido à recente instituição da estratégia e-SUS AB, o seu processo de implantação está em evolução em todo o país, e estudos já revelam fragilidades que comprometem sua legitimação, gerando efeitos no processo de trabalho e no cotidiano dos profissionais da $\mathrm{ABS}^{8-10}$. Além disso, o sucesso na implantação da estratégia e-SUS AB também depende de sua adoção pelos diversos atores humanos envolvidos, e que, de fato, seja adaptado ao contexto da $\mathrm{ABS}^{8,11}$.

Outrossim, em uma estratégia que visa informatizar todo o serviço de ABS, de um país com extensa dimensão territorial e de diversidade econômica e sociocultural como o Brasil, faz-se necessário ir além de uma abordagem meramente tecnicista, onde geralmente as avaliaçóes possuem seu enfoque na eficácia e eficiência das tecnologias de informação ${ }^{12}$. É preciso conhecer a rede de atores humanos e não humanos tecida durante a implantação dessa estratégia de informatização em um determinado tempo e lugar.

Neste contexto, atores humanos e não humanos - também denominados "actantes" - se relacionam em rede, a qual é entendida como a associação entre estes entes, bem como as trocas intensas entre suas conexões, envolvendo a ideia de vários nós e múltiplas relações, permitindo-nos acompanhar e delinear a produção dos fenômenos. Os múltiplos actantes, em suas interaçôes, tecem a rede com base em intencionalidades, ou seja, emitem traduções (transformaçôes) sobre a rede, influenciando continuamente a construção dos fenômenos sociais ${ }^{13}$.

Assim, é preciso conhecer a rede de atores e suas influências sobre a estratégia e-SUS $\mathrm{AB}$ com vistas a aperfeiçoar sua implantação em todo o país. Desta feita, questiona-se: Como se conforma a rede de atores e suas influências sobre a informatização da atenção 
básica à saúde? Para responder essa questão, propomos neste artigo: analisar a rede de atores e suas influências sobre a informatização da atenção básica à saúde.

\section{Metodologia}

Trata-se de um estudo baseado na teoria ator-rede (TAR $)^{13}$ como referencial teórico e a cartografia de controvérsias ${ }^{14}$ como referencial metodológico. A TAR possui como proposição acompanhar os movimentos dos actantes e as influências que decorrem entre seus vínculos. A narrativa dos eventos é considerada a essência de sua teoria, que, por sua vez, emerge das manifestações e movimentos dos atores. O seu objetivo é mapear, ao máximo, as associações e delinear a dinâmica da rede, rastreando o ator no ato de sua agência e cartografando seus lastros ${ }^{13}$.

A cartografia de controvérsias é considerada como um conjunto de técnicas para explorar e visualizar polêmicas e controvérsias, observando e descrevendo o debate social, especialmente - mas não exclusivamente - em torno dos problemas técnicocientíficos ${ }^{14}$. Contempla quatro movimentos a serem percorridos ${ }^{15}$. O primeiro movimento trata-se de buscar uma porta de entrada na rede. Neste estudo, a porta de entrada, foi a Secretaria Municipal de Saúde (SMS) de um município do Oeste de Minas Gerais, escolhido intencionalmente por sua parceria com a universidade gestora da pesquisa e por estar em fase de implantação da estratégia e-SUS AB. $\mathrm{Na}$ SMS escolhida como porta de entrada, atuavam os envolvidos no processo de implantação, de onde partiam as determinações para as Unidade Básicas de Saúde (UBS) e se planejava toda a informatização, as capacitaçôes e também onde se recebia as determinaçóes do Ministério da Saúde. Para, de fato, entrar na rede, um dos pesquisadores se vinculou ao município como voluntário, participando ativamente na implantação da estratégia e-SUS AB no município.

Além da esfera local, representada pelas UBS do município e SMS, uma Superintendência Regional de Saúde (SRS), a Secretaria Estadual de Saúde de Minas Gerais (SES) e o Ministério da Saúde também foram mapeados compondo a rede em análise. Entretanto, tais esferas foram mapeadas à medida que os atores transitavam por estes cenários, e assim foram seguidos, conforme preconizado pelo referencial metodológico proposto ${ }^{15}$.

No segundo movimento, devem-se identificar os porta-vozes que falam pela rede, faz-se importante ouvir tanto os atores concordantes quanto os discordantes ${ }^{15}$. Como o manual de implantação da estratégia e-SUS AB orienta que, em cada município, devem-se eleger dois profissionais como responsáveis pelo processo de implantação, designou-se esses profissionais como potenciais porta-vozes iniciais. Desde então, os pesquisadores passaram a segui-los e a mapear suas ligaçóes com outros atores da rede, inclusive com os divergentes, identificando assim, até o final da coleta de dados, 54 atores humanos na rede.

Os pesquisadores foram remetidos aos demais participantes da pesquisa tendo em vista a importância destes para a composição da rede estudada, uma vez que os mesmos estavam diretamente envolvidos com a implantação da estratégia e-SUS AB.

O processo de caminhar pela rede se deu, em maior tempo, por meio de observaçóes participante. A observação participante proporciona, ao pesquisador cartográfico, maiores evidências dos rastros deixados pelos atores, culminando, assim, em um 
mapeamento com mais propriedade do fenômeno ${ }^{13}$. As observações aos 54 atores humanos geraram Notas de Observação (NO), as quais foram inscritas em um diário de campo.

As observaçóes ocorreram a partir da participação do pesquisador na implantação da estratégia e-SUS AB no município. Assim, juntamente com os porta-vozes: utilizou os sistemas de software, participou das reunióes entre os profissionais envolvidos com a informatização; participou dos encontros semanais entre a coordenação da $\mathrm{AB}$ e profissionais do município, e realizou capacitaçóes relacionadas ao processo de informatização.

Do total de 54 atores humanos seguidos e observados, 14 foram entrevistados no intuito de se compreenderem algumas situaçóes que emergiam das observaçóes e que necessitavam de esclarecimento. A técnica da entrevista proporciona, ao pesquisador cartográfico, uma retificação de suas interpretações ${ }^{16}$. As entrevistas se deram na modalidade aberta, duraram, em média, cinquenta minutos e foram audiogravadas e transcritas para um banco de dados. Juntamente com o diário de campo, tais inscriçóes compuseram a narrativa do caso estudado.

Assim, os atores humanos do estudo foram: enfermeiros (ENF), dentistas, médicos (MED), profissionais do Núcleo de Apoio à Saúde da Família (NASF), profissionais técnicos/administrativos (PROF TEC/ADM), técnicos de enfermagem (TEC ENF), Agentes Comunitários de Saúde (ACS), recepcionistas de UBS (RECEP), técnico em informática, auxiliares de odontologia (AUX DENT), coordenadores (CO), gestores e responsáveis técnicos (RESP). Com atuação nos seguintes cenários: UBS, SMS, NASF, Centro de Especialidades Odontológicas (CEO), SRS e SES. Os atores humanos foram codificados de acordo com sua categoria profissional, local de atuação e ordem de aparecimento.

O terceiro movimento define a necessidade de se acessarem os dispositivos de inscrição, ou seja, tudo o que representa uma exposição visual de qualquer tipo, e possibilite "objetivar" a rede ${ }^{15}$. De agosto de 2016 a setembro de 2017, foram catalogados 121 dispositivos de inscrição acerca da estratégia e-SUS AB, tais como: manuais, portarias, diretrizes, editais, minutas, notas técnicas, of ícios, planilhas e políticas.

Por último, no quarto movimento, foram mapeadas as associaçôes ${ }^{15}$ entre os actantes da rede. Delinearam-se as relaçóes que se estabeleceram entre os diversos actantes que compuseram a rede, destacando as múltiplas traduções produzidas pelos atores envolvidos na informatização, ressaltando-se suas articulações, em especial: os efeitos de sinergia ou de cooperação na rede; os efeitos de encadeamento ou de repercussão da rede; as cristalizações ou limitaçóes da rede.

Com vistas à sistematização do mapeamento das associaçôes, realizaram-se os seguintes procedimentos propostos no referencial metodológico utilizado ${ }^{17}$ :

Leitura extenuante das informações extraídas dos dispositivos de inscrição, das notas de observaçóes e das entrevistas;

Descrição em profundidade da dinâmica social do fenômeno estudado; e reagregação dos acontecimentos em ordem cronológica;

Eleição dos actantes mediadores (aqueles que modificam a rede) diretamente envolvidos com o objeto em estudo; 
Identificação das ligações entre os actantes mediadores com base na descrição do caso em estudo (as ligaçôes são consideradas existentes quando, entre dois actantes, há algum tipo de relação - conflito, acordo, divergência, questionamentos, sinergias, dentre outros);

Criação de um banco de dados contendo 69 nós (actantes mediadores) e 517 arestas (ligaçốes).

Para explorar e entender as ligaçôes entre os actantes da rede, utilizaram-se as ferramentas de exposição visual do software Gephi $0.9 .1^{18}$, por meio da importação do banco de dados criado pelos pesquisadores para o "Laboratório de Dados" do software.

Cada nó da rede Gephi foi representado por um ator, e sua espessura e o tamanho de sua fonte corresponderam ao número de arestas (Grau) que este possuiu com os demais nós. Entende-se por aresta a ligação entre dois nós, correspondendo, assim, às interaçôes entre esses entes.

Às arestas atribuiu-se o tipo "não dirigido", ou seja, quando a ligação entre dois nós é necessariamente recíproca. Na elaboração da planilha de arestas deve-se atribuir um "peso" (relevância) a cada ligação; para este estudo definiu-se que todas as ligações continham peso igual a 1 pois, o objetivo não era graduar a força das relaçóes, mas apenas a sua existência. A identificação dos nós e as ligações entre eles foram baseadas em evidências contidas nos dispositivos de inscrição, nas notas de observações e nas entrevistas.

$\mathrm{Na}$ aba de "visão geral" do software, procedeu-se aos seguintes trâmites na aparência da rede: execução da estatística "modularidade", que mede a força da divisão de uma rede em "módulos", dividindo os nós de uma rede em grupos, de acordo com suas conexôes - quanto mais interconectado está um grupo de nós, maiores as chances de eles constituírem um módulo na rede; coloração dos nós a partir da função "Partition Modularity Class"; e tamanho dos nós e da fonte de acordo com seu "Grau”.

Com base nessas disposiçóes, o software gerou automaticamente a rede, alocando seus nós por afinidades de ligaçôes e dando origem a aglomerados de nós fortemente conectados denominados de "Clusters", os quais representam grupos de interesses comuns, que são diferenciados por cores para facilitar as interpretações.

Para uma organização da rede, ainda na aba de "visão geral", fez-se o uso do algoritmo de layout padrão "ForceAtlas 2", cujo objetivo foi representar espacialmente as ligaçôes entre nós pertencentes a distintos clusters, de forma a criar um "mapa" de suas conexões.

Também se fez o uso da técnica "Extratos de relatos com ponto de vista da Teoria Ator-Rede" ${ }^{19}$. Nesta técnica analítica são extraídos trechos das descrições que ilustram as ligaçốes presentes na rede. Tais trechos auxiliam a compreensão da interação entre os actantes e foram providenciais para se proceder com a interpretação da rede e extrair significados a partir dos conceitos da TAR.

O estudo obedeceu a Resolução 466/2012 do Conselho Nacional de Saúde e foi submetido ao Comitê de Ética em Pesquisa com Seres Humanos, da Universidade Federal de São João del-Rei - Campus Centro-Oeste Dona Lindu, o qual obteve sua aprovação sob parecer de №: 1.384 .632 . 


\section{Resultados e discussão}

A rede apresentou 4 clusters (Figura 1), sendo o de cor roxa o maior cluster, com 30 nós $(44,12 \%)$. Este cluster é basicamente composto por actantes que atuam na SMS envolvidos com a implantação da estratégia e-SUS AB e não humanos representantes da esfera federal de governo do Sistema Único de Saúde brasileiro.

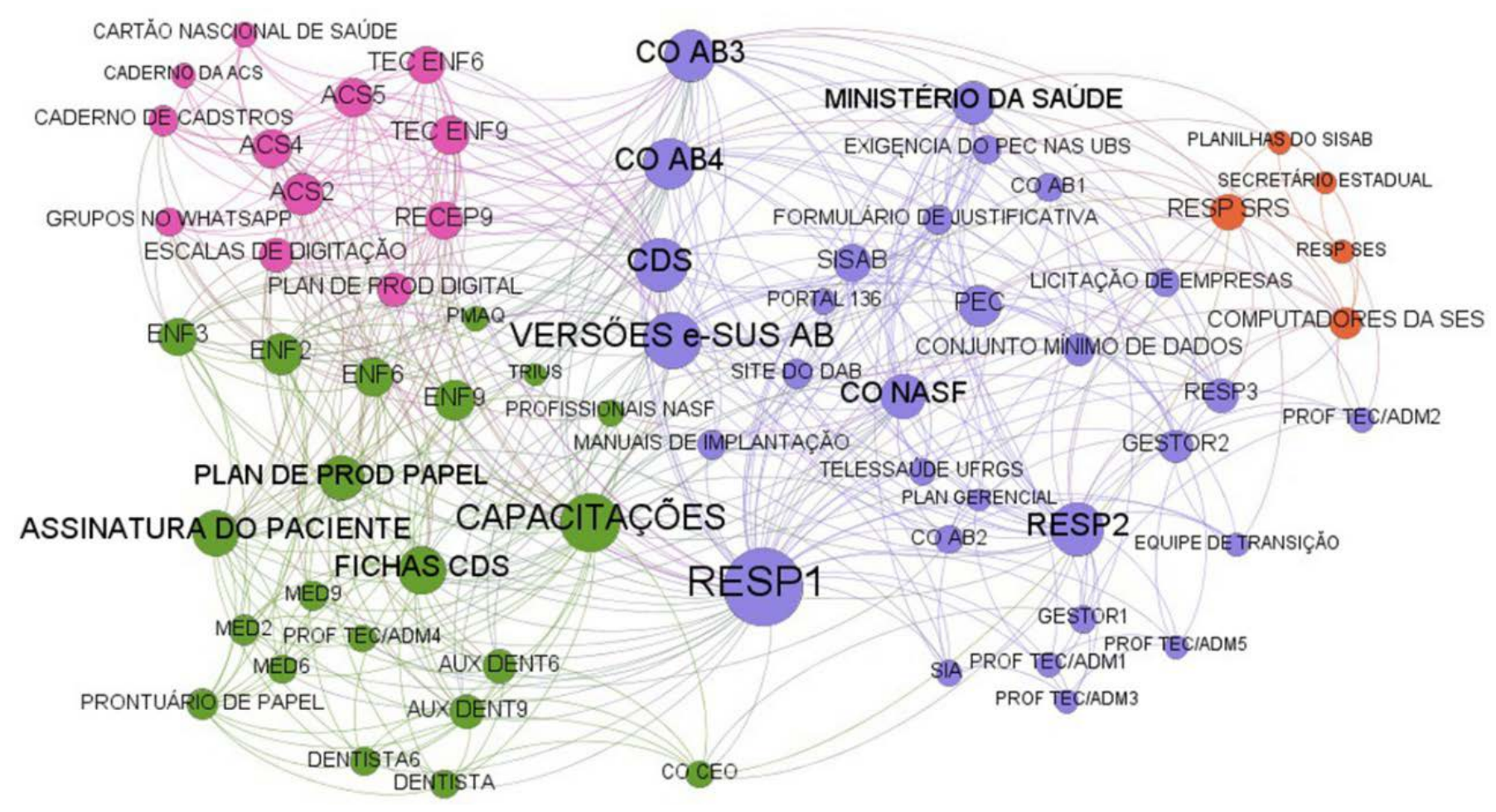

Figura 1. A rede de atores humanos e não humanos da estratégia e-SUS AB, na esfera municipal - 2018.

Um dos nós da rede, o Ministério da Saúde, atua definindo obrigatoriedades e penalidades por meio de não humanos (portarias, ofícios, manuais, diretrizes, atualizaçôes de versôes, canais de comunicação, dentre outros). $\mathrm{O}$ trecho a seguir destaca essa forma da esfera de governo federal de se fazer presente na rede, bem como de nortear a informatização estudada.

[...] a partir da competência de janeiro de 2016 as informações deverão ser enviadas obrigatoriamente para a base de dados de SISAB. Diante disso, a ausência de envio de informaçóes para o SISAB por três (3) competências consecutivas, ocasiona a suspensão de recursos do Bloco da Atenção Básica $[\ldots]^{20} \cdot($ p. 1$)$

Esses resultados demonstram que a implantação da estratégia e-SUS AB foi desencadeada por meio de não humanos (políticas e normativas) da esfera federal do governo brasileiro definindo obrigatoriedades e penalidades, sobretudo na esfera municipal. São inscrições que pontualizam traduções de uma rede de atores ${ }^{21}$, 
intencionalidades da esfera federal, com vista a influenciar a rede de actantes tecida no âmbito regional e municipal, determinando uma estratégia de informatização padronizada.

Esta forma de implantar tecnologias da informação na saúde pública brasileira tem contribuído para a inadequação das tecnologias às realidades locais; e a criação de significados equivocados onde tais tecnologias são compreendidas como instrumentos burocráticos sobrecarregando o cotidiano de trabalho ${ }^{4,22}$.

É no cluster roxo que se encontra o maior nó da rede, o RESP1 (Primeiro profissional cadastrado no Ministério da Saúde como responsável pelo processo de implantação da estratégia e-SUS AB no município). Seu destaque é fruto do elevado número de ligaçóes com os demais atores, conformando-se como principal porta-voz do processo de implantação, tanto no relacionamento com outras esferas governamentais, quanto como referência para os profissionais do município. Ao se extrair apenas sua rede de ligaçóes (Figura 2), é possível visualizar tal conformação.

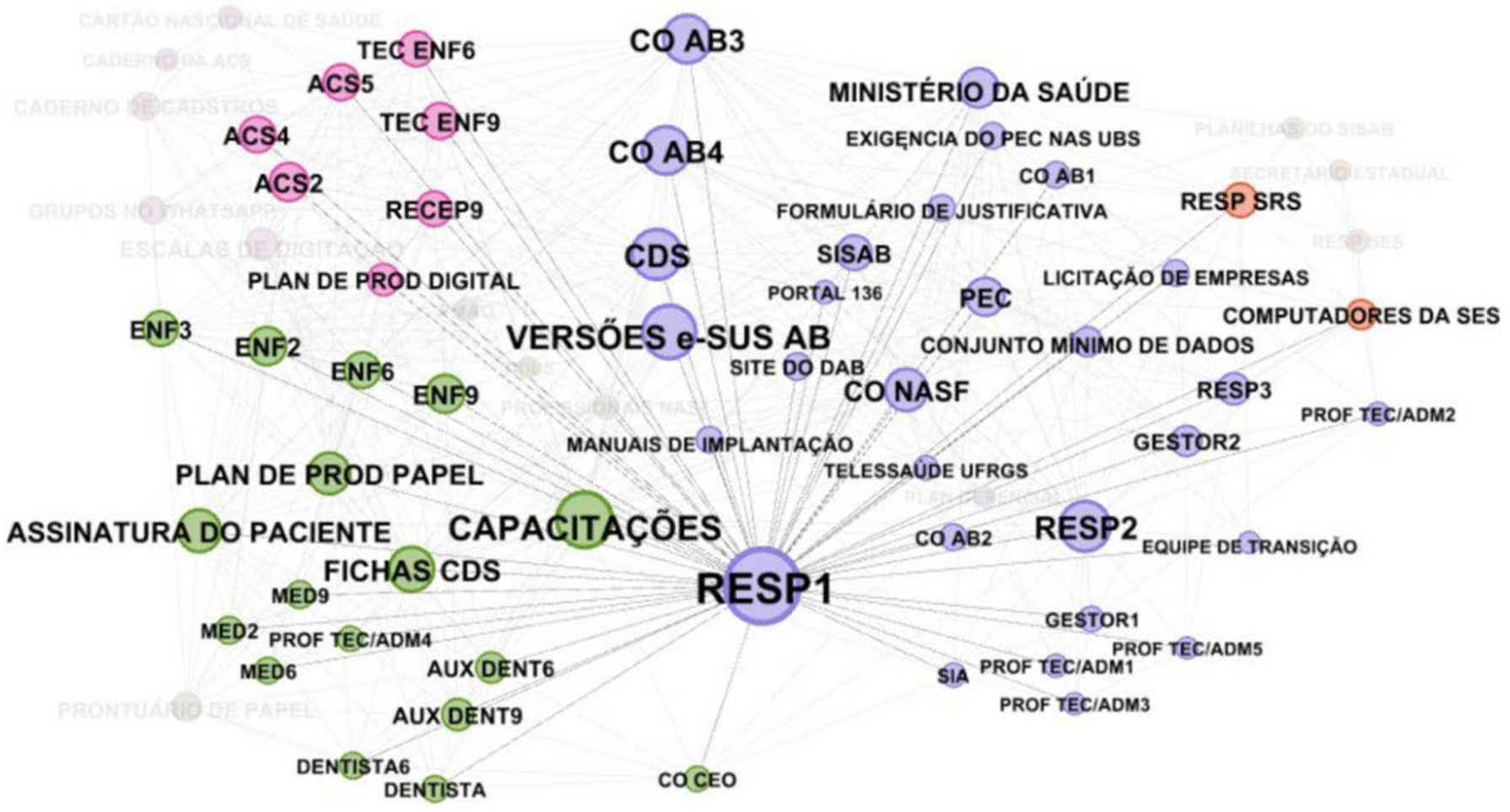

Figura 2. Rede de ligações pertencentes ao nó "RESP1" (Responsável municipal 1), da rede de actantes da estratégia e-SUS AB, na esfera municipal - 2018.

Outros atores em destaque no cluster roxo são: RESP2, $\mathrm{CO}$ AB3 e CO AB4 que, juntamente com RESP1, conformaram-se como os gestores responsáveis pelo processo de implantação da estratégia e-SUS AB no município. No mesmo período, a coordenação da $\mathrm{AB}$ foi ocupada por quatro humanos diferentes $(\mathrm{CO} A B 1, \mathrm{CO} A B 2$, $\mathrm{CO} \mathrm{AB} 3, \mathrm{CO} \mathrm{AB} 4$ ) representando alta rotatividade dos gestores responsáveis, como destacado no trecho a seguir.

"No continuum de seguir $\mathrm{CO} A B 2$, a mesma me apresentou o profissional que iria substituí-la no mês seguinte, o CO AB4. Em pouco mais de nove meses, este 
seria o quarto coordenador da $\mathrm{AB}$ do município, o próximo responsável pela implantação da estratégia e-SUS AB.” (NO)

Ainda no cluster roxo, outro nó proeminente foi VERSÕES e-SUS AB. Tratase das várias atualizaçóes do software CDS realizadas pelo Ministério da Saúde e disponibilizadas aos municípios, por meio do SITE DO DAB. A cada nova versão, alteraçóes eram feitas no layout do software e, consequentemente, nas FICHAS CDS, influenciando, assim, o cotidiano dos envolvidos, uma vez que a cada nova atualização, capacitações e reformulações do processo de trabalho se faziam necessárias:

"Acompanhei o RESP2 na instalação da mais nova versão (versão 2.1) na máquina da CO NASF (tratava-se da quarta versão do software em menos de dois anos de uso). Percebi que a mesma notava uma série de diferenças na interface do software e enfrentava diversos obstáculos. RESP2 disponibilizou à ela o manual de utilização da nova versão baixado do site do DAB, porém CO NASF alegou não ter condiçóes de estudá-lo, uma vez que o mesmo continha 302 páginas.” $(\mathrm{NO})$

O cluster laranja, o menor da rede, conta com cinco nós (7,35\%) e representam os atores da SRS e SES que, de alguma forma, atuam no município com vistas à implantação da estratégia e-SUS AB. Seu maior nó é o da responsável técnica pela estratégia e-SUS AB na Região Ampliada de Saúde Oeste de Minas Gerais (RESP SRS). Ao se extrair sua rede (Figura 3), observam-se ligaçóes com não humanos do Ministério da Saúde, com todos os actantes da SES e com todos os humanos envolvidos no processo de implantação da estratégia na SMS, sobretudo gestores, configurando-se como um importante mediador entre essas esferas governamentais.

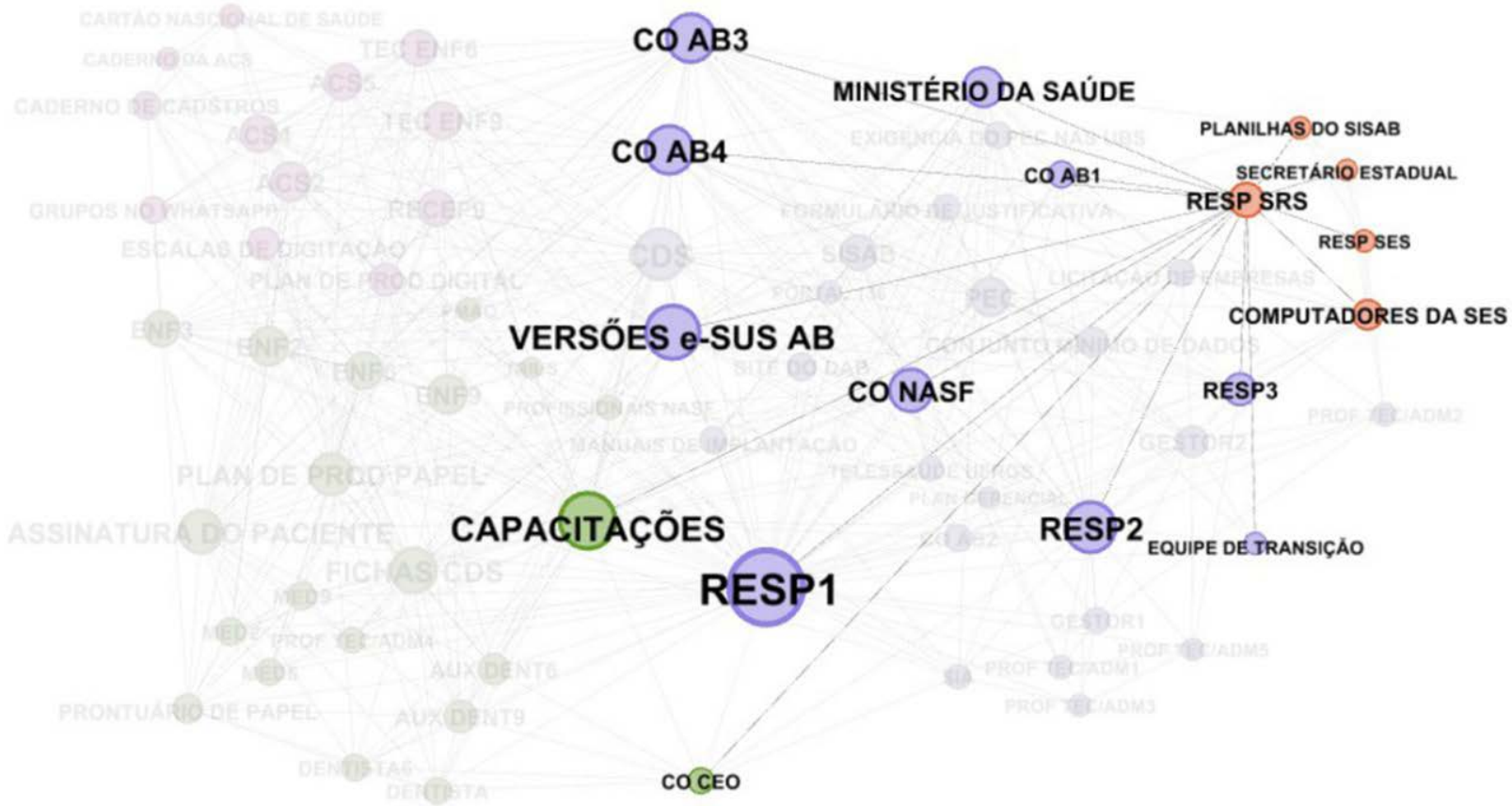

Figura 3. Rede de ligações pertencentes ao nó "RESP SRS" (Responsável Técnico na Superintendência Regional de Saúde), da rede de actantes da estratégia e-SUS AB, na esfera municipal - 2018 
O segundo maior cluster da rede com 21 nós (30,88\%) é o de cor verde. Todos os profissionais de nível Superior que trabalham nas UBS relacionadas no estudo estão inseridos nesse cluster. Seus maiores nós são: "capacitação", "fichas CDS”, "PLAN de PROD papel" e "assinatura do paciente", não humanos que representam a forma como a estratégia e-SUS AB vem sendo implantada nas UBS: por meio do preenchimento de Planilhas de Produção vinculadas com o cumprimento de metas e o repasse de verbas federais; a exigência da "assinatura do paciente" nessas planilhas; o retrabalho; o preenchimento das "fichas CDS" em papel; o preenchimento do "prontuário de papel” dos pacientes; a transcrição dos dados coletados para o software CDS no computador. A cena a seguir demonstra algumas destas situaçóes.

"Esse processo de "realimentação" de dados, gera uma série de "retrabalhos". Há também a coexistência de papel e tecnologia, mas com predominância do primeiro. Assim, o dado colhido na UBS pelo profissional é registrado fisicamente em uma ficha CDS, depois no prontuário de papel do paciente que fica arquivado na UBS e depois na planilha de produção, onde se recolhe a assinatura do cidadão. Esse mesmo profissional tem que transcrever as informações da ficha CDS para o software CDS, além de compilar a quantidade de procedimentos/atendimento realizados na semana, diretamente na planilha de produção digital.” (NO)

O nó mais proeminente do cluster verde é CAPACITAÇÕES, isso se deve ao fato de esta comunidade apresentar o maior número de actantes envolvidos nos momentos de capacitação desenvolvidos na rede. No entanto, ao se extrair a rede de ligaçóes deste não humano (Figura 4), observa-se que se faz presente, a partir de ligaçóes, em todos os clusters, conformando-o como um elemento de articulação entre tais comunidades.

O principal provedor de capacitações da rede foi RESP1, por isso a proximidade entre ambos os nós. Apesar das capacitações como elo de ligação entre os cluster da rede, algumas fragilidades de tal processo emergiram dos discursos dos atores, tais como: "[...] desde quando eu entrei, eu aprendi sozinha, eu não tive quem me ensinasse, então como se diz, eu tive que ir na coragem, na cara e na coragem para aprender $[\ldots . . . "$ (ACS2).

Tais fragilidades acabam por gerar algumas traduçóes entre esses atores, a primeira é a delegação da digitação da produção de vários profissionais pelo ACS: "Não tive capacitação. $\mathrm{Na}$ verdade, eu tô sendo muito franco com você, eu nem sei pra quê que serve isso aqui [...] só falaram assim: 'simplesmente vocês vão ter que preencher essa ficha' [...] e quem preenche é a ACS” (MED2).

Outra tradução, trata-se de um acordo mediado por RESP1 e CO AB2, onde parte dos médicos de saúde da família do município teriam suas fichas CDS de atendimento individual digitadas no software por um profissional, que foi remanejado de outro setor da SMS. 
(2)

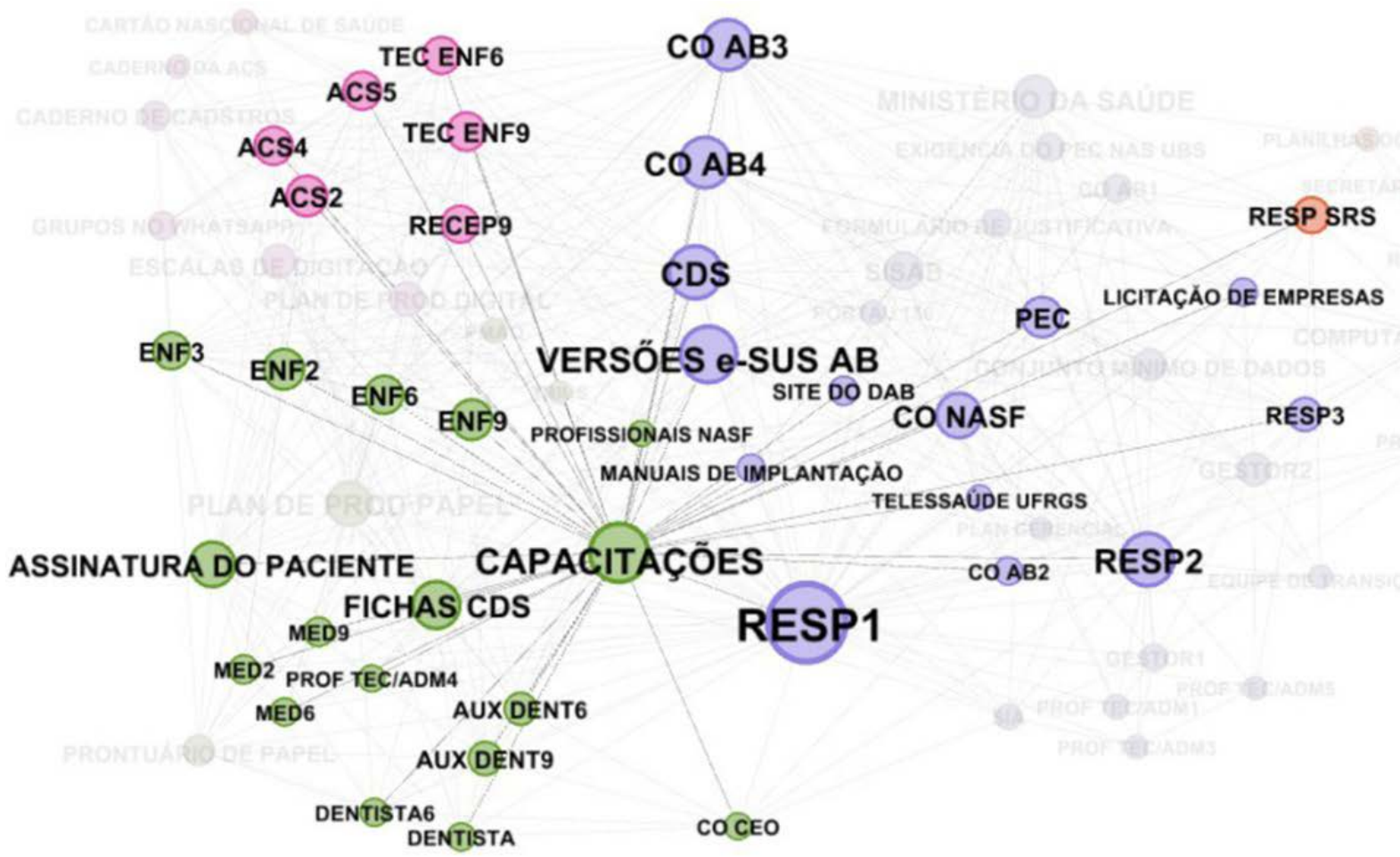

Figura 4. Rede de ligações pertencentes ao nó "capacitações" da rede de actantes da estratégia e-SUS AB, na esfera municipal - 2018.

"Com a adesão do município à estratégia e-SUS AB, RESP1 enfrentou resistências por parte dos médicos, para digitarem suas fichas CDS de atendimento individual. Alegavam ter que diminuir o número de atendimentos à população para digitarem suas produçóes. Então a coordenadora da $\mathrm{AB}$ à época, $\mathrm{CO} A B 2$, sugeriu à RESP1 a delegação de tal atribuição à um profissional que se encontrava ocioso em outro setor de saúde.” (NO)

De fato, essa tradução não gerou diminuição do número de atendimentos à população, no entanto, emitiu influências negativas no registro de dados médicos do município:

"Cada médico preenche de uma determinada forma e PROF TEC/ADM4 reclamava dessa falta de padronização. Alguns médicos costumavam relatar os procedimentos nas bordas das fichas, na maioria das vezes sem listar o CID10 e com letras ilegíveis.” (NO)

Os próprios profissionais defendem o fato de que devem digitar a produção e os dados gerados pelo atendimento médico. Assim tecem acordos:

"Eu fiz um acordo com a médica assim, oh eu digito todas as suas fichas de atendimento no CDS, e aí você atende pelo menos mais três pacientes por dia 
[...] eu prefiro digitar e ela fazer três visitas a mais na semana [...] eu acho muito mais que ela deve servir a população do que ela ficar atrás do computador [...]” (ENF9)

Os médicos também reconheceram que não deveriam assumir a digitação de sua produção, pois isso prejudicaria o seu número de atendimentos diários.

"[...] eu não sei praticamente nada, porque eu nem tenho contato, [...] nem sei direito dessa ficha, porque quem preenche pra mim é a ENF9. [...] aquilo demora demais por isso que eu não preencho [...] se você for fazer direito, não tem jeito, você gasta uma hora. [...]" (MED9)

Por sua vez, o cluster rosa apresentou 12 nós (17,65\%), dos quais representam os ACS envolvidos com os cadastros das famílias e alguns técnicos de enfermagem responsáveis pelo fechamento da produção de saúde nas UBS.

Devido à escassez de computadores nas UBS, diante da demanda de digitação dos profissionais, as enfermeiras criaram a "escala de digitação", inclusive para profissionais que não estão sob sua supervisão. Outra tradução das enfermeiras foi a criação de um "caderno de cadastros", que era usado como uma espécie de banco de dados da UBS. A cena a seguir destaca tal tradução:

"Como ninguém sabia extrair relatórios do CDS, uma das enfermeiras (ENF6) criou uma tabela e exigiu que na capa de cada caderno de cadastro houvesse um condensado de acompanhamento por cada microárea, com o número total de famílias, hipertensos, diabéticos, gestantes, fumantes, deficientes físicos, crianças até dois anos, crianças até cinco anos, pacientes em uso de benzodiazepínicos, mulheres de 18 a 69 anos, beneficiários do bolsa família e portadores de doença pulmonar obstrutiva crônica.” (NO)

Assim como as enfermeiras, as ACS também desenvolveram um dispositivo para inscreverem os dados de saúde da população, visto que não havia no município fichas CDS em número suficiente para essa categoria profissional.

"As ACS registram a visita em seus cadernos, duplicando o registro, e o fazem para se resguardarem caso algum paciente alegue não ter sido visitado. Assim ao término da visita o cidadão tem que assinar a planilha de produção física que segue para SMS e o caderno da ACS, para respaldo da mesma. O registro é diversificado e segue as intencionalidades de cada ACS em registrar ao seu modus, não há uma preocupação com a sistemática do registro, mas sim em comprovar de alguma forma que a visita foi realizada e garantir anotaçóes de tudo que foi realizado nesta visita, bem como o registro de suas impressóes.” $(\mathrm{NO})$

Nesse contexto, as informações passaram a ser registradas em novos dispositivos de inscrição criados pelos profissionais de saúde, com vistas a materializar as demandas informacionais que eram incompatíveis com as fichas CDS, ou por falta da mesma. Ao se plotar a rede de ligaçôes do "caderno de cadastro" e "caderno da ACS” (Figura 5), 
pode-se observar que estes actantes não possuem ligaçóes com nenhum ator dos cluster roxo e laranja, demonstrando que se trata de uma tradução desenvolvida no cotidiano de trabalho das UBS e não institucionalizada por outros atores da esfera municipal, regional ou federal.
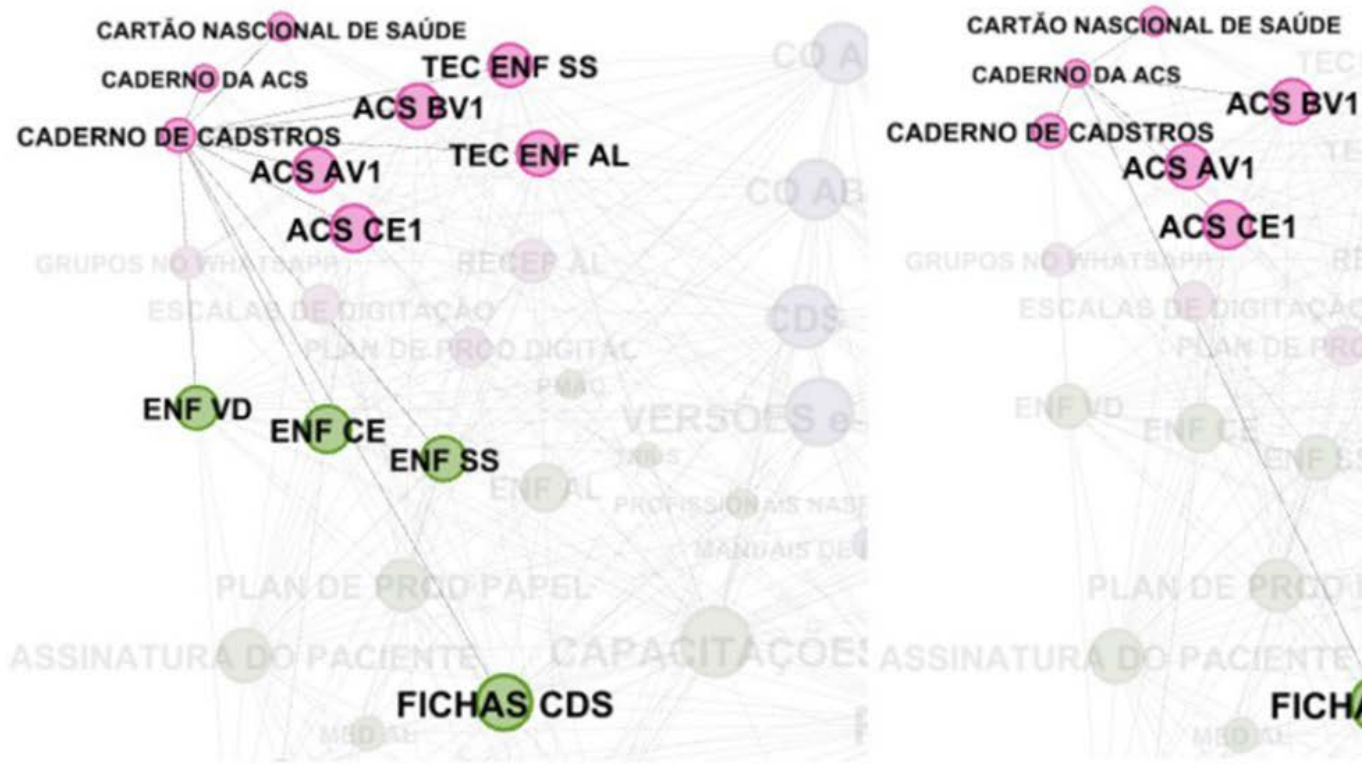

Figura 5. Redes de ligações pertencentes ao nó "caderno de cadastro" (esquerda) e ao nó "caderno da ACS" (direita), da rede de actantes da estratégia e-SUS AB, na esfera municipal $-2018$.

Encontra-se também no cluster rosa o não humano "grupos de Whatsapp" - tratase de canais de comunicação, outra tradução, desenvolvida por alguns profissionais no interior das UBS com vistas a trocas de experiências sobre a estratégia e-SUS AB: "[...] Tem também os grupinhos de whatsapp que a gente criou, cada uma das meninas vai postando uma coisa nova que descobriu no e-SUS [...]" (ACS4).

A rede de actantes envolvida com a implantação da estratégia e-SUS AB também é tecida a partir de traduções dos profissionais de saúde, tais como: a delegação de funções a alguns profissionais (ACS, digitadores) em detrimento de outros que se afastam do processo de informatização (médicos); a criação de outros dispositivos de registro em papel sem a garantia da qualidade e sem a padronização das informaçóes registradas; os acordos (troca de favores) relacionados com o processo de alimentação dos sistemas de software. São modificações proporcionadas pelos atores sobre a rede ${ }^{13}$, tornando-a dinâmica e, em parte, divergente das normativas e diretrizes de implantação.

As traduçôes aqui verificadas se conformam como adaptaçôes dos profissionais e de seu cotidiano de trabalho estimuladas pelo processo de informatização vivenciado. São adaptações que, apesar de buscarem cumprir a ordem de alimentar os sistemas de software, o fazem à sua maneira, perante acordos e invençóes próprias. Na dinâmica social, a forma como cada ator interpreta o fenômeno e o (re)inventa é particular de suas concepçóes e princípios ${ }^{23}$. Ademais, tendo em vista que a conformação da rede 
está sempre em ação ${ }^{24}$, sua estrutura diz respeito às traduções existentes no decorrer das associações, designando, assim, a apropriação singular que cada ator faz da rede e na rede, moldando-a segundo as suas vontades e acordos, de modo que, o ator não age simplesmente, ele é levado a agir pela capacidade de decodificação dos anseios de outros atores ${ }^{15}$.

Por mais que a implantação da estratégia e-SUS AB tenha normas e parametrizações, há também actantes que traduzem outras formas de informatizar, tecem suas ligaçôes e interações em rede, influenciam e são influenciados, caracterizando o processo de implantar tecnologias como algo que vai além da disponibilização de hardware, software e suporte tecnológico.

O não humano não é apenas um artefato, cujo significado é sempre atribuído pelo humano, e sim, ele passa a possuir capacidade de agência, participando e até mesmo protagonizando a ação social, recebendo e provocando transformaçôes ${ }^{13}$. As entidades (humanos e não humanos) são constituídas e adquirem seus atributos por meio do conjunto de relaçóes que estabelecem com outras entidades, a partir de associaçóes que são tecidas em rede ${ }^{25}$. Neste sentido, o sucesso na implantação de tecnologias da informação no contexto da $\mathrm{ABS}$ depende da relação estabelecida entre humanos e não humanos e das invençóes e transformaçóes que ocorrem no cotidiano de trabalho.

Neste sentido, além da esfera federal, que influencia a forma como a implantação da estratégia e-SUS AB deve acontecer, os profissionais também emitem suas influências sobre a forma como ela vem sendo implantada, e o fazem a partir de: traduçóes, modificaçôes no processo de trabalho, nas relaçôes com outros profissionais, nas criaçôes de novos dispositivos de registro, dentre outros.

A alta rotatividade dos gestores atrelada a questóes políticas obstaculizou o processo de implantação da estratégia e-SUS AB na rede estudada. Além disso, as atualizações das versões dos softwares, o preenchimento de fichas em papel e sua transcrição para o software CDS, a elaboração de planilhas de produção vinculadas ao cumprimento de metas e ao repasse de verbas influenciaram o processo de trabalho dos profissionais, gerando sobrecarga de trabalho e tensóes.

Essas situaçóes são advindas da relação entre os actantes da rede, e tendem a gerar resistências ao processo de informatização ${ }^{9}$, fortalecendo a percepção equivocada de que a estratégia e-SUS AB é uma invenção descolada das demandas reais das $\mathrm{UBS}^{26}$. Essas situações também são circunstanciais e geradoras de comportamentos, pois, pressionam os profissionais a desenvolverem atitudes em relação à tecnologia e, assim, influenciam a implantação de uma estratégia de informatização. A imaturidade e complexidade dos processos envolvidos durante uma experiência de informatização também acabam por gerar resistências por parte de seus usuários, potencializando assim o seu insucesso ${ }^{27}$.

Alguns nós (RESP1, RESP SRS, CAPACITAÇÕES) conformaram-se como cruciais para o processo de implantação da estratégia e-SUS AB, pois eram comuns a todos os clusters da rede e, portanto, ligavam as comunidades. Estes nós podem ser considerados como Pontos de Passagem Obrigatória, ou seja, rotas mobilizadas por diversas negociaçóes e trocas entre os atores, para que ocorra a alteração de suas preferências, em prol de um objetivo comum, o qual estabelece uma ligação na rede entre os atores ${ }^{28}$. Desta feita, tais nós são importantes actantes de mediação (mediadores), e portanto de transformação da rede ${ }^{13}$. Informações difundidas a partir destes actantes podem ser disseminadas para as várias comunidades da rede e contribuir 
efetivamente para a implantação da estratégia e-SUS AB. Entretanto, reconhecemos que tais actantes também precisam ser fortalecidos, as capacitações são um exemplo, no sentido de ampliar sua capacidade de articulação na rede. Se isso acontecer, é possível fortalecer o processo de informatização da ABS.

Estes achados reforçam o fato de que o sucesso na implantação de projetos de informatização em saúde depende de identificar e empoderar pontos de passagem obrigatória, de tal modo que os demais actantes da rede desloquem suas trajetórias no intuito de alcançarem o objetivo em comum e, consequentemente, reconheçam as tecnologias da informação como potencializadoras de decisóes assertivas baseadas em informaçốes qualificadas ${ }^{29}$.

A mobilização para implantar um projeto de informatização deve ser um esforço coletivo, e não apenas de alguns profissionais, ou do responsável pela gestão do process $^{30}$. Os profissionais precisam se engajar no sentido de contribuir para a modernização do seu processo de trabalho a partir da inserção de tecnologias da informação ${ }^{31}$. Não é possível o médico, por exemplo, se esquivar deste contexto, como verificado neste estudo. Tal profissional faz parte da equipe, sua função, assim como a dos demais profissionais de saúde, exige participar do registro qualificado das informaçôes produzidas no processo de trabalho.

\section{Considerações finais}

Neste estudo analisamos a rede de atores humanos e não humanos e suas traduções sobre a informatização da Atenção Básica à Saúde. Verificamos que a rede estudada é tecida entre humanos e não humanos representantes das várias esferas de governo. A esfera federal emite inscrições (políticas, penalidades e obrigatoriedades) que são traduçôes de suas intencionalidades e se fazem presentes, sobretudo, nos contextos regional e local. Esta forma de implantar tecnologias, a partir de penalidades e obrigatoriedades, não tem contribuído para o sucesso da informatização.

Nas esferas local, estadual e regional, os profissionais e gestores modificam a rede por meio da criação de dispositivos de inscrição, adequam processos de trabalho, estabelecem invençôes, tecem acordos em rede que acabam precarizando a informatização da ABS e conformam-se como desafios a serem suplantados.

Cientes do dinamismo da rede, pois a implantação da estratégia e-SUS AB é contínua e ainda se encontra em evolução, limitando-nos a cartografá-la até um determinado momento histórico e a partir do caminhar pela rede, sendo remetidos pelos porta-vozes iniciais. Tais escolhas metodológicas não trouxeram à tona, neste estudo, as influências de atores técnico-políticos notoriamente relevantes para o cenário de implantação da estratégia e-SUS AB, como: a Universidade Federal de Santa Catarina (UFSC), os órgãos de controle federais e as empresas locais prestadoras de serviços de Tecnologia da Informação.

Assim sendo, novas cartografias podem revelar novos actantes, traduçóes e, portanto, novas influências sobre o processo de informatização. Além disso, é preciso investigar a utilização dos sistemas de software (CDS e PEC), e de seus dispositivos móveis (tablets) sobre: a organização do trabalho, a gestão do cuidado e a tomada de decisões gerenciais. 


\section{Contribuições dos autores}

Ricardo Bezerra Cavalcante: Elaboração do projeto, coleta de dados, análise e discussão dos dados resultantes do estudo, elaboração, revisão crítica e aprovação da versão final do manuscrito. Cristiano José da Silva Esteves: Elaboração do projeto, coleta de dados, análise e discussão dos dados resultantes do estudo, elaboração e submissão, revisão crítica e aprovação da versão final do manuscrito. Tarcísio Laerte Gontijo: Elaboração do projeto, análise e discussão dos dados do estudo, revisão crítica e aprovação da versão final do manuscrito. Maria José Menezes Brito e Eliete Albano de Azevedo Guimarães: Análise e discussão dos dados do estudo, revisão crítica e aprovação da versão final do manuscrito.

\section{Agradecimentos}

À Fundação de Amparo à Pesquisa do Estado de Minas Gerais (FAPEMIG), ao Conselho Nacional de Desenvolvimento Científico e Tecnológico (CNPQ) e ao Ministério da Saúde brasileiro (MS), pelo financiamento da pesquisa.

\section{Direitos autorais}

Este artigo está licenciado sob a Licença Internacional Creative Commons 4.0, tipo BY (https://creativecommons.org/licenses/by/4.0/deed.pt_BR).

$(\mathrm{cc})$

\section{Referências}

1. Santos AF, Sobrinho DF, Araújo LL, Procópio CSD, Lopes EAS, Lima AMLD, et al. Incorporação de tecnologias de informação e comunicação e qualidade na atenção básica em saúde no Brasil. Cad Saude Publica. 2017; 33(5):1-14.

2. Fornazin M, Joia LA. Articulando perspectivas teóricas para analisar a informática em saúde no Brasil. Saude Soc. 2015; 24(1):46-60.

3. Cardoso RB, Ferreira BJ, Martins WA, Paludeto SB. Programa de educação permanente para o uso do prontuário eletrônico do paciente na enfermagem. J Health Inform. 2017; 9(1):25-30.

4. Santos TO, Pereira LP, Silveira DT. Implantação de sistemas informatizados na saúde: uma revisão sistemática. Reciis. 2017; 11(3):1-11.

5. Ministério da Saúde (BR). Portaria no 1.412, de 10 de Julho de 2013. Institui o Sistema de Informação para a Atenção Básica (SISAB). Brasília: Ministério da Saúde; 2013.

6. Paz LF, Maran V, Machado A, Augustin I. MECA: mobile system support for brazilian community health agents program based on context-awareness. IEEE Lat Am Trans. 2017; 15(8):1547-55.

7. Cavalcante RB, Watanabe YJA, Esteves CJS. Informatização qualificada do Sistema Único de Saúde: estratégia e-SUS Atenção Básica. In: Kalinowski CE, Crozeta K, Costa MFBNA, organizadores. PROENF Programa de Atualização em Enfermagem: atenção primária e saúde da família: ciclo4. Porto Alegre: Artmed Panamericana; 2016. p. 57-82.

8. Cavalcante RB, Vasconcelos DD, Gontijo TL, Guimarães EAA, Machado RM, Oliveira VC. Informatização da atenção básica a saúde: avanços e desafios. Cogitare Enferm. 2018; 23(3):e54297. 
9. Oliveira AEC, Lima IMB, Nascimento JA, Coelho HFC, Santos SR. Implantação do e-SUS AB no Distrito Sanitário IV de João Pessoa (PB): relato de experiência. Saude Debate. 2016; 40(109):212-8.

10. Astolfo S, Kehrig RT. O processo de implantação de uma estratégia integrada de SIS na APS no Mato Grosso, Brasil. Rev Saude Colet. 2017; 7(1):8-15.

11. Medeiros JB, Holmes ES, Albuquerque SGE, Santos SR, Candeia RMS, Costa T. O e-SUS Atenção Básica e a coleta de dados simplificada: relatos da implementação em uma estratégia saúde da família. Rev APS. 2017; 20(1):145-9.

12. Camillis PK, Bussular CZ, Antonello CS. A agência a partir da Teoria Ator-Rede: reflexôes e contribuiçốes para as pesquisas em administração. Organ Soc. 2016; 23(76):73-91.

13. Latour B. Reagregando o social: uma introdução à teoria do Ator-Rede. SalvadorBauru: EDUFBA-EDUSC; 2012.

14. Venturini T. Diving in magma: how to explore controversies with actor-network theory. Public Underst Sci. 2010; 19(3):258-73.

15. Pedro R. Sobre redes e controvérsias: ferramentas para compor cartografias psicossociais. In: Ferreira AAL, Freire LL, Moraes M, Arendt RJJ, organizadores. Teoria Ator-Rede e Psicologia. Rio de Janeiro: Nau; 2010. p. 78-97.

16. Latour B, Woolgar S. A vida de laboratório: a produção dos fatos científicos. Rio de Janeiro: Relume Dumará; 1997.

17. Venturini T, Ricci D, Mauri M, Kimbell L, Meunier A. Designing controversies and their publics. Des Issues. 2015; 31(3):74-87.

18. Jacomy M, Venturini T, Heymann S, Bastian M. ForceAtlas2, a continuous graph layout algorithm for handy network visualization designed for the Gephi software. PLoS One. 2014; 9(6):e98679.

19. Pinto C, Domenico CS. Análise de dados na Teoria Ator-Rede-contribuiçóes via cartografia de controvérsias aos estudos em administração. CIAIQ2014. 2015; 3:123-9.

20. Ministério da Saúde (BR). Secretaria de Atenção à Saúde. Departamento de Atenção Básica. Ofício Circular 044/2016-DAB/SAS/MS. Suspensão por ausência de envio de informações das equipes de atenção básica por meio de sistema de informação vigente na Atenção Básica - e-SUS AB/SISAB. Brasília: Ministério da Saúde; 2016.

21. Law J. Notes on the theory of the Actor-Networking: ordering, strategy and heterogeneity. Syst Pract. 1992; 5(3):379-3.

22. Associação Brasileira de Pós-Graduação em Saúde Coletiva (ABRASCO), Grupo Técnico de Informação em Saúde e População (GTISP), organizadores. Plano Diretor para o desenvolvimento da Informação e Tecnologia de Informação em Saúde - PlaDITIS 2013-2017: no contexto da atual governança de informação e de implantação do Registro Eletrônico em Saúde/RES. Brasília: ABRASCO; 2013.

23. Law J. Traduction/Trahison: notes on ANT. Convergencia. 2006; 13(42):47-72.

24. Venturini T, Munk A, Jacomy M. Actor-network VS network analysis VS digital networks are we talking about the same networks? Galaxia (São Paulo). 2018; (38):527.

25. Law J. After ANT: complexity, naming and topology. In: Law J, Hassard J, organizadores. Actor-Network Theory and after. London: Blackwell; 1999. p. 1-14. 
26. Ministério da Saúde (BR). Secretaria de Atenção à Saúde. Departamento de Atenção Básica. e-SUS Atenção Básica Manual de implantação (Versão preliminar - em fase de diagramação). Brasília: Ministério da Saúde; 2014.

27. Kuziemsky CE. Review of social and organizational issues in health information technology. Healthc Inform Res. 2015; 21(3):152-60.

28. Callon M. Some elements of a sociology of translation: domestication of the scallops and the fisherman of St Brieuc Bay. Sociol Rev. 1984; 32(1):196-233.

29. Fornazin M, Joia LA. Remontando a rede de atores na implantação de um sistema de informação em saúde. Rev Adm Empres. 2015; 55(5):527-38.

30. Ingebrigtsen T, Georgiou A, Clay-Williams R, Magrabi F, Hordern A, Prgomet M, et al. The impact of clinical leadership on health information technology adoption: systematic review. Int J Med Inform. 2014; 83(6):393-405.

31. Nguyen L, Bellucci E, Nguyen LT. Electronic health records implementation: an evaluation of information system impact and contingency factors. Int J Med Inform. 2014; 83(11):779-96.

Drawing on the Actor-Network theory, this study investigated networks of actors and their influence on the informatization of Primary Healthcare. The cartography of controversies method was used, involving the observation and interviewing of actors from the municipal, regional, state, and federal spheres, together with the collection of published documents. The data was analyzed using the software Gephi and the selection of extracts from the interviews based on the actor-network approach. The mapped network is woven between humans and nonhumans in the different spheres of government. Policies and obligations were shaped into the guiding principles of informatization, pressuring professionals and managers to adapt processes and weave agreements to enable informatization, yet with little success. It is concluded that circumstantial translations in the different spheres of government influence the informatization of primary care in the pursuit of success, but have not yet proved effective for such purpose.

Keywords: Health informatics. Information technologies. Primary healthcare.

Estudio basado en la teoría Actor-Red con el objetivo de analizar la red de actores y sus influencias sobre la informatización de la Atención Básica de la Salud. La Cartografía de controversias dirigió la trayectoria metodológica, en la que actores humanos de la esfera municipal, regional, estadual y federal fueron observados y entrevistados, además de la colecta de documentos publicizados. Los datos se observaron por medio del software Gephi y a través de la técnica de extractos de relatos con punto de vista de la Teoría Actor-Red. La red mapeada se teje entre humanos y nohumanos en las diferentes esferas de gobierno. Las políticas y obligatoriedades se conformaron como inscripciones regidoras de la informatización, presionando a profesionales y gestores para que adecuasen procesos y tejieran acuerdos para viabilizar la informatización, pero con poco éxito. Se concluye que traducciones circunstanciales en las diferentes esferas gubernamentales influyeron en la informatización de la atención primaria, buscando su éxito, pero todavía no se mostraron efectivas en ese sentido.

Palabras clave: Informática en salud. Tecnologías de la información. Atención básica de la salud. 